\title{
Mediastinal Masses: Pathophysiological Issues and Management Challenges in a Developing World
}

\author{
Martins Oluwafemi Thomas, Ezekiel O. Ogunleye \\ Lagos University Teaching Hospital/College of Medicine of University of Lagos, Lagos, Nigeria \\ E-mail: oluwafemithomas@yahoo.com \\ Received January 10, 2011; revised March 24, 2011; accepted April 12, 2011.
}

\begin{abstract}
Context: Mediastinal masses occur worldwide. Compartmental occurrence and pathological variants vary widely, hence, the need for more studies. AIM: The study was conducted to further shed light on pathophysiological and current management challenges of mediastinal masses. Settings and Design: It was a prospective hospital based study spanning a period of 5 years. Methods and Materials: We gathered patients in series noting their ages and sex, presenting symptoms, investigation reports, treatment modalities and associated postoperative complications. Statistical Analysis Used: Data was analysed manually looking at frequency distribution, correlation of malignancy with compartment involved and duration of symptoms against incidence of malignancy. Results: We saw 38 patients with significant male preponderance. Most tumours were in anterior mediastinum and population distribution was leptokurtic. Conclusions: Population distribution of mediastinal masses is leptokurtic. The second to the fourth decades of life are mostly affected. There was no correlation between occurrence of malignancy and the mediastinal compartment involved. Most benign tumours are symptomatic and duration of symptoms is not discriminatory between benign and malignant variants. Occurrence of malignancy had no bearing with duration of symptoms. If less than two months, it became significant at sixth month when benignity was positively correlated with long duration of symptoms.
\end{abstract}

Keywords: Mediastinal Masses Management Challenges

\section{Introduction}

The mediastinum is the space between the two lungs. The space is protected by the rigid anterior and posterior chest walls. Much of the space is occupied by the heart and the great vessels. The other components include lymph nodes and thoracic ducts to mention a few. Any of these component organs can become enlarged thereby becoming symptomatic or even asymptomatic. Mediastinal tumours benign or malignant may be primary or secondary, congenital or acquired [1-4]. Most benign tumours are primary to the mediastinum in location but cervico-mediastinal tumours are also fairly common. They are mostly solid tumours, but may be cystic or mixed.

Benign masses present mostly with pressure symptoms. They also present with endocrine symptoms. Malignant masses may present with pressure or constitutional symptoms. However some tumours may present with atypical symptoms. Ankermann and his colleagues [5] found three paediatric cases that presented like bronchial asthma. Critical mediastinal mass with propensity to cause respiratory symptoms in children is associated with the followings: anterior location of the mediastinal mass, histological diagnosis of lymphoma, presence of superior vena caval obstruction, radiological evidence of vessel compression or displacement, pericardial effusion and pleural effusion [6].

The histological patterns also vary widely. The common benign tumours of the antero-superior mediastinum include thyroid masses, thymomas and vascular tumours to mention a few. The middle mediastinum is dominated by the pericardial masses while the posterior mediastinum is dominated by neurogenic tumours like ganglioneuromas.

While an earlier report from Ibadan, southwest Nigeria confirmed lymphomas as the commonest primary mediastinal masses, [7] Lam and his colleagues [6] in Singapore found neurogenic tumour as the commonest his- 
tologic variant. Some of the rare tumours of the mediastinum include sarcoma of follicular dendritic cells in the posterior mediastinum, non seminomatous germ cell tumour, adenomatoid tumour, mediastinal extramedullary haemopoietic tumour, thoracic duct cysts and cervicothoracic schwannoma. [8-12]

In view of the internal location of most mediastinal masses, symptomatology has to be supported by imaging techniques to define the tumours. Diagnosis was based mainly on clinical features and standard chest radiographs in Nigeria till about a decade ago [13]. Fine needle aspiration has been tried by authors from Saudi Arabia [9] and another team in Ibadan. [10] Personal experience, though not published shows that the gold standard nowadays for the diagnosis of mediastinal masses is imaging, and it has reduced the incidence of diagnostic thoracotomy in the management of such masses.

Access to the mediastinum is usually through a thoracotomy or sternotomy incision but a cervical approach may suffice for some cervicomediastinal lesions. More recently, endoscopic computer-enhanced mediastinal mass resection using robotic technology is being done thorough minimal access [14]. This is associated with shorter hospitalisation because surgical trauma is minimised.

This work was done to study the pathophysiological issues and management challenges of mediastinal masses.

\section{Subjects and Methods}

The design of the study was for a prospective and hospital based setting spanning five years in the metropolitan Lagos, Nigeria. We created a protocol for entering the relevant data. These data included patients' demography with special note of age and sex. We took note of the presenting symptoms, report of investigations stating the location of the mass, treatment modality and specific associated operative and postoperative complications. We excluded vascular masses like thoracic aneurysms and all masses that were treated with chemotherapy and radiotherapy. We only included the surgically treated cases.

The data was subsequently analysed. We looked at the frequency distribution of the data.

We also looked at the duration of symptoms vis-à-vis the incidence of malignancy and we sought correlation between mediastinal compartment involved and occurrence of malignancy.

\section{Results}

There were 38 patients with Mediastinal masses in 5 years. They consisted of 29 males and 9 females giving a
Male: Female ratio of 3.2:1.

The antero-superior Mediastinal masses dominated with 29 patients (76.3\%) while $18.4 \%$ and $2.6 \%$ were found in the posterior and middle mediastinum respectively (Table 1). The sample population had a mean age of $33.7 \pm 10.0$ years. The median of 32.7 was close to the mean and it was marginally leptokurtic. This means that the distribution was close to normal with a Pearson Skewness of +0.30

We saw 17 thyroid masses constituting 44.7\%, 10 patients had lymphomas constituting $26.3 \%$ and 7cases of neurogenic tumour $18.4 \%$. Others were 3 thymic tumours (7.9\%) and only one pericardial cyst (2.6\%).

The asymptomatic patients were $13(34.2 \%)$ in all. They were incidental findings on chest radiographs.

There was no correlation between occurrence of malignancy and the mediastinal compartment involved. This correlation could not be tested with the middle mediastinum because we saw only one middle mediastinal mass.

There was also no correlation between duration of symptoms and occurrence of malignancy as tested with arbitrary durations of one and two month durations respectively. The position changed at the $6^{\text {th }}$ month where $87.3 \%$ were found to be benign.

\section{Discussion}

Tumours of the mediastinum are either primary or secondary. Management of mediastinal tumours can be challenging. The reasons for this have to do with the need for complex or sophisticated facilities for diagnosis and treatment. This often limits the diagnosis and treatment of such tumours.

In our study, we saw 38 patients who had mediastinal masses in five years. This constituted an annual hospital-based occurrence of 7.6 cases and it was nearly double the occurrence of mediastinal masses in Ibadan, a centre 120 kilometres North-east of our centre [7] within

Table 1. Age \& sex distribution and locations.

\begin{tabular}{ccccccc}
\hline $\begin{array}{c}\text { Age Range } \\
(\mathrm{yrs})\end{array}$ & $\mathrm{M}$ & $\mathrm{F}$ & Antero-superior & Middle & Posterior & Total \\
\hline$<10$ & 1 & - & 1 & - & - & 1 \\
$11-20$ & 1 & - & 1 & - & - & 1 \\
$21-30$ & 10 & 2 & 11 & - & 1 & 12 \\
$31-40$ & 13 & 4 & 13 & 1 & 3 & 17 \\
$41-50$ & 2 & 3 & 3 & - & 2 & 5 \\
$51-60$ & 1 & - & - & - & 1 & 1 \\
$>60$ & 1 & - & - & - & - & 1 \\
Total & 29 & 9 & 29 & 1 & 7 & 38 \\
\hline
\end{tabular}


the same period. We have no good explanation for the increased occurrence at our centre.

Our study showed a male preponderance of $76.3 \%$. This is very close to the finding of $71.4 \%$ in the same study (vide supra) conducted over a 24-year period.

The mean age in our series was $33.7 \pm 10$ years. It is fairly close to the mean of $35.2 \pm 22.1$ years found in a similar report for the same region [13]. Cumulatively, $76.3 \%$ of the affected patients in our series were in the $3^{\text {rd }}$ and $4^{\text {th }}$ decades of life with a skew towards the $4^{\text {th }}$ decade.

More than 2/3 of the tumours were in the antero-superior mediastinum, followed by less than $20 \%$ in the posterior mediastinum and the middle mediastinum harboured only one case. This distribution is quite similar to positions held by earlier authors $[7,13]$.

Thyroid masses contributed $44.7 \%$ of the tumours while lymphomas and neurogenic tumours were $26.3 \%$ and $18.4 \%$ respectively. This contrasts with earlier positions where lymphomas, thymic tumours and thyroid masses were found in reducing order $[7,13]$.

Majority of our patients were symptomatic at presentation. In all, $65.8 \%$ presented with varying symptoms leaving only $34.2 \%$ as incidental findings. Even at that, the asymptomatic group is still very significant and it might constitute a good reason for routine screening of patients in the $2^{\text {nd }}$ and $3^{\text {rd }}$ decades of life.

There is no particular preference of malignant tumours for any mediastinal compartment. Also, within a period of 2months of symptoms, there was no correlation between occurrence of malignancy and duration of symptoms to an extent that $87.3 \%$ of cases were found to be benign.

We therefore concluded that long duration of symptoms ( $>6$ months) is a pointer to benignity of mediastinal tumours.

\section{References}

[1] Y. Zhang, S. R. Yang, D. U. Cheng and J. Guan "Clinical and Pathological Features of Congenital Bronchial Cyst," Chinese Journal of Tuberculosis and Respiratory, Vol. 26, No. 10, 2003, pp. 619- 622.

[2] L. H. Cheng and F. C. Wells, "A Multidisciplinary Approach to Recurrent Cervicothoracic Cystic Hygroma in an Adult," Britain Journal of Maxillofac Surgery, Vol. 42, No. 1, 2004, pp. 66-68. doi:10.1016/S0266-4356(03)00173-6

[3] N. S. Adzick "Management of Foetal Lung Lesions," Clinics in Perinatology, Vol. 30, No. 3, 2003, pp. 481-

\section{2. doi:10.1016/S0095-5108(03)00047-2}

[4] J. H. Kim, J. M. Goo, H. J. Lee, M. J. Chung, S. I. Jung, Lim KY, M. W. Lee and J. G. Im, "Cystic Tumours in the Anterior Mediastinum. Radiologic-Pathological Correlation,” Journal of Computer Assisted Tomography, Vol. 27, No. 5, 2003, pp. 714-723. doi:10.1097/00004728-200309000-00008

[5] T. Ankermann, A. Claviez and M.Suttorp, "Mediastinal tumour in Children Initially Misdiagnosed and Treated as Bronchial Asthma,” Dtsch Med Wochenschr, Vol. 129, No. 12, 2004, pp. 613-616. doi:10.1055/s-2004-820570

[6] J. C. Lam, C. H. Chui, A. S. Jacobsen, A. M. Tan and V. T. Joseph, "When is a Mediastinal Mass Critical in a Child? An Analysis of 29 Patients," Pediatric Surgery International, Vol. 20, 2004, pp. 180-184. doi:10.1007/s00383-004-1142-6

[7] V. O. Adegboye, A. O. Ogunsehinde, M. O. Obajimi, O. Ogunbiyi, A. I. Brimmo, O. A. Adebo, "Presentation of Primary Mediastinal Masses in Ibadan," East African Medical Journal, Vol. 80, No. 9, 2003, pp. 484-487.

[8] S. M. Krober, A. Marx, H. Aebert, B. M. Dohmen, E. Kaiserling, "Sarcoma of Follicular Dendritic Cells in the Dorsal Mediastinum,” Human Pathology, Vol. 35, No. 2, 2004, pp. 259-263. doi:10.1016/j.humpath.2003.09.008

[9] Y. M. Al-Marzooq, A. T. Al-Bahrani, R. Chopra, M. I. Al-Momatten "Fine Needle Aspiration Biopsy Diagnosis of Intrathoracic Extramedullary Hematopoiesis Presenting as a Posterior Mediastinal Tumour in a Patient with Sickle-Cell Disease: Case Report," Diagnostic Cytopathology, Vol. 30, No. 2, 2004, pp. 119-121. doi:10.1002/dc.10421

[10] D. O. Irabor, J. K. Ladipo, F. N. Nwachokor, J. O. Thomas, "Schwannoma of the Left Branchial Plexus Mimicking a Cervicomediastinal Gotre in a Young Nigerian Lady,” West African Journal of Medicine, 21, 3, 2002, pp. 195-196.

[11] J. A. Plaza, F. Dominguez, S. Suster, "Cystic Adenomatous Tumour of the Mediastinum," American Journal of Surgical Pathology, 2004, Vol. 28, No. 1, pp. 132-138. doi:10.1097/00000478-200401000-00016

[12] C. S. Pramesh, M. S. Deshpande, G. H. Pantvaidya, S. Sharma, R. K. Deshpande, "Thoracic duct cyst of the mediastinum," Annals of Thoracic and Cardiovascular Surgery, Vol. 9, No. 4, 2003, pp. 264-265.

[13] V. O. Adegboye, A. I. Brimmo, O. A. Adebo, O. O. Ogunsehinde, M. O. Obajimi, "The place of clinical features and standard chest radiography in evaluation of mediastinal masses," West African Journal of Medicine, Vol. 22, No. 2, 2003, pp. 156-160.

[14] J. A. Morgan, T. Kohmoto, C. R. Smith, M. C. Oz and M. Argeziano, "Endoscopic Computer-Enhanced Mediastinal Mass Resection using Robotic Technology,” Heart Surgery Forum, Vol. 6, No. 6, 2003, pp. E164-166. 